\title{
Cost-Effectiveness of Treatment Strategies with Biologics in Accordance with Treatment Guidelines for Ankylosing Spondylitis: A Patient-Level Model
}

\author{
Quang A. Le, PharmD, PhD; Jenny H. Kang, PharmD; Sun Lee, PharmD; and Dimittri Delevry, PharmD
}

\begin{abstract}
BACKGROUND: Ankylosing spondylitis (AS) is a form of rheumatic disease caused by chronic inflammation of the axial skeleton. Patients with AS experience significant functional limitations and reduced quality of life. Consequently, AS imposes a substantial economic burden on society due to productivity loss and work disability. Biologics, including tumor necrosis factor (TNF) inhibitors and human anti-interleukin-17A monoclonal antibody (IL-17A) agents, are effective treatment strategies in relieving symptoms and slowing down disease progression. Currently, 5 TNF inhibitors and 2 IL-17A antibody agents are approved by the FDA for the management of AS. Of these agents, there is no clear preferred agent in initial biologic therapy, although an IL-17A antibody agent or alternative TNF inhibitor agent is recommended after failure of the initial TNF inhibitor therapy.

OBJECTIVE: To assess cost-effectiveness of treatment strategies with biologics, TNF inhibitor or IL-17A, in accordance with the treatment guidelines for patients with AS.
\end{abstract}

METHODS: An economic patient-level simulation combining decision-tree and Markov models was constructed from the U.S. health care payer's perspective over a 10-year time horizon. The current model examined 5 treatment strategies: (1) conventional care treatment with nonsteroidal anti-inflammatory drugs, (2) 1 TNF inhibitor, (3) an IL-17A antibody agent, (4) sequential therapy with 2 TNF inhibitors, and (5) sequential therapy with a TNF inhibitor followed by an IL-17A antibody agent. Initially, treatment responses were determined after 12-week treatments. Patients who responded to treatment entered a "responders" Markov model. Patients entered a "nonresponders" Markov model if they inadequately responded to treatment. In sequential treatment strategies, patients who inadequately responded to treatment with the first TNF inhibitor received a second TNF inhibitor or an IL-17A antibody agent. Health utility was estimated based on the Bath Ankylosing Spondylitis Disease Activity Index (BASDAI) and Functional Index (BASFI) scores. The models accounted for real-world adherence to TNF inhibitor treatment. Scenario and probabilistic sensitivity analyses were performed to test the robustness and uncertainty of the model results.

RESULTS: Over a 10-year time horizon and 100,000 simulated patients for each treatment strategy, base-case results produced average total discounted per-patient costs of $\$ 19,765, \$ 130,302, \$ 159,934, \$ 190,553$, and $\$ 179,118$ and quality-adjusted life-years (QALYs) of $4.675,5.410$, $5.499,5.919$, and 5.893 for conventional care, treatment strategies with 1 TNF inhibitor, an IL-17A, 2 TNF inhibitors, and a TNF inhibitor followed by an IL-17A, respectively. The optimal treatments at willingness-to-pay (WTP) thresholds $\leq \$ 130,813$ per QALY, between $\$ 130,813$ per QALY and $\$ 442,728$ per QALY, and $>\$ 442,728$ per QALY were conventional care and sequential treatment strategies with 1 TNF inhibitor, followed by an IL-17A agent and 2 TNF inhibitors, respectively.
CONCLUSIONS: Study findings suggested that all treatment strategies with biologics, TNF inhibitors or IL-17A antibody agents, in the treatment guidelines for AS were not cost-effective at the common WTP of $\$ 100,000$ per QALY. However, the sequential treatment with $1 \mathrm{TNF}$ inhibitor followed by an IL-17A antibody agent was considered cost-effective at a higher WTP of $\$ 150,000$ per QALY.

J Manag Care Spec Pharm. 2020;26(10):1219-31

Copyright $\odot 2020$, Academy of Managed Care Pharmacy. All rights reserved.

\section{What is already known about this subject}

Biologics, such as tumor necrosis factor (TNF) inhibitors, a class of biologic disease-modifying antirheumatic drugs, and human anti-interleukin-17A monoclonal antibody (IL-17A), are an effective treatment strategy in relieving symptoms and slowing down disease progression in ankylosing spondylitis (AS).

Treatment guidelines indicate no preference among 5 FDAapproved TNF inhibitors and 2 IL-17A antibody agents for management of AS.

An IL-17A agent or an alternative TNF inhibitor is recommended after failure of the initial TNF inhibitor therapy as a sequential therapy.

\section{What this study adds}

This is the first economic evaluation study that examines the cost-effectiveness of treatment strategies with biologics according to the treatment guidelines for patients with AS from the U.S. health care payer's perspective.

This study suggests that all treatment strategies with biologics, TNF inhibitors or IL-17A agents, in the treatment guidelines for AS were not cost-effective at the common willingness-to-pay (WTP) threshold of $\$ 100,000$ per quality-adjusted life-years (QALY); however, the sequential treatment strategy with $1 \mathrm{TNF}$ inhibitor followed by an IL-17A agent was considered costeffective at a higher WTP of $\$ 150,000$ per QALY.

A nkylosing spondylitis (AS) is a form of rheumatic disease caused by chronic inflammation of the axial skeleton involving the sacroiliac joints and spine. ${ }^{1} \mathrm{~A}$ recent study reported an increase in the prevalence of AS from 
$0.04 \%$ to $0.09 \%$ of the U.S. population from 2006 to 2016, with a larger proportion of males affected compared with females. ${ }^{2}$ Patients with AS often experience symptoms such as aches, stiffness, and pains in the lower back and hips beginning from early adulthood; as a result, they endure significant functional limitations and reduced quality of life. ${ }^{3}$ Furthermore, AS imposes a substantial economic burden on society with considerable productivity loss due to sick leave and work disability. ${ }^{4}$ Before the introduction of tumor necrosis factor (TNF) inhibitors, the cost of AS was primarily driven by the cost of the disease and its consequences on productivity loss. ${ }^{5}$ As TNF inhibitors and human anti-interleukin-17A monoclonal antibodies (IL-17A) were shown to be an effective treatment strategy and incorporated in the management of AS, the overall direct costs associated with treatment of AS increased substantially. ${ }^{6}$ In 2012, the total U.S. direct costs of AS were estimated at about $\$ 6,514$ and $\$ 11,162$ for medical costs and prescription drug costs per patient per year, respectively. ${ }^{6}$

To date, no treatment is available to reverse the structural damage caused by AS. Current therapy options focus on relief of AS symptoms associated with destructive joint inflammation. ${ }^{7}$ The Spondyloarthritis Research and Treatment Network, American College of Rheumatology, Spondylitis Association of America, Assessment of Spondyloarthritis International Society, and European League Against Rheumatism recommend nonsteroidal anti-inflammatory drugs (NSAIDs) as the first-line therapy (i.e., conventional care) in the management of AS. ${ }^{8}$ For those who fail to respond or develop adverse reactions to NSAID therapy, TNF inhibitors, a class of biologic disease-modifying antirheumatic drugs, or an IL-17A antibody agent is considered an effective treatment strategy in relieving symptoms and slowing down disease progression. ${ }^{8-10}$

Currently, 5 TNF inhibitors-golimumab (approved in 2009), certolizumab pegol (2008), adalimumab (2002), etanercept (1998), and infliximab (1998) —in addition to 2 IL-17A antibody agents—secukinumab (2016) and ixekizumab (2019)—are approved by the U.S. Food and Drug Administration for the management of AS. Of these, there is no clear preference in initial TNF inhibitor or IL-17A therapy; although, an IL-17A or alternative TNF inhibitor agent is recommended after failure of the initial TNF inhibitor therapy as sequential therapy. ${ }^{8}$

Despite their potential benefits in delaying disease progression and improving patient quality of life, the high treatment cost of TNF inhibitors and IL-17A antibody agents in the management of AS warrants an economic evaluation. ${ }^{11}$ Recent meta-analysis studies and clinical trials showed that patients treated with a TNF inhibitor or an IL-17A antibody were 2-4 times more likely to achieve treatment response compared with conventional care. ${ }^{12-17}$

In addition, whether sequential treatment with 2 TNF inhibitors or 1 TNF inhibitor followed by an IL-17A antibody agent provides better value in health care compared with transitioning back to conventional care remains to be seen. Furthermore, to the best of our knowledge, no studies have been conducted to evaluate the cost-effectiveness of sequential treatment strategies after failing to achieve an adequate response to an initial TNF inhibitor as recommended by the current treatment guidelines for patients with AS.

To facilitate health care decision making for the use of an IL-17A antibody agent or TNF inhibitor in further-line therapy, the purpose of this study was to evaluate the cost-effectiveness of treatment strategies with biologics in accordance with the treatment guidelines for patients with AS.

\section{Methods}

\section{Modeling Approach}

A patient-level modeling approach that combined decisiontree and Markov models was developed using Visual Basic for Application programming with Microsoft Excel front end (Microsoft, Redmond, WA) to evaluate the cost-effectiveness of treatment strategies in accordance with the treatment guidelines for patients with AS. The current model examined 5 treatment strategies $^{8}$ : (1) conventional care (treatment with NSAIDs); (2) 1 TNF inhibitor (treatment with 1 of the 5 approved TNF inhibitors: adalimumab, certolizumab pegol, etanercept, golimumab, or infliximab); (3) an IL-17A antibody agent (either secukinumab or ixekizumab); (4) sequential therapy with 2 TNF inhibitors (1 TNF inhibitor followed by an alternative TNF inhibitor); and (5) sequential therapy with a TNF inhibitor followed by an IL-17A antibody agent.

Initially, treatment responses were generated at the end of a 12-week treatment based on recent meta-analyses of TNF inhibitors and related clinical trials of IL-17A antibody agents for treatment of AS (Figure 1).12-17 Patients who responded to treatment would enter a "responders" Markov model with 3 health states (Appendix A, available in online article), while those who did not respond to treatment entered a "nonresponders" Markov model with 2 health states (Appendix B, available in online article). In the responders Markov model, patients would continue to receive active treatment ("continued treatment" health state), drop out from active treatment and enter the nonresponders Markov model ("withdrawn treatment" health state), or die ("death" health state) based on their respective age and standardized mortality ratio for AS (Appendix A). On the other hand, patients would receive conventional care and assume further functional deterioration until death or the end of model time horizon if entering the nonresponders Markov model (Appendix B).

In sequential treatment strategies, patients who inadequately responded to treatment with the first TNF inhibitor received a second TNF inhibitor or an IL-17A antibody agent. Treatment response was then reassessed at 12 weeks to determine 
FIGURE 1 Structure of Hybrid Model for Treatment of AS for Conventional Care with NSAIDs, 1 TNF Inhibitor, an IL-17A Antibody Agent, Sequential Treatment Strategy with 2 TNF Inhibitors, and Sequential Treatment Strategy with a TNF Inhibitor followed by an IL-17A Antibody Agent

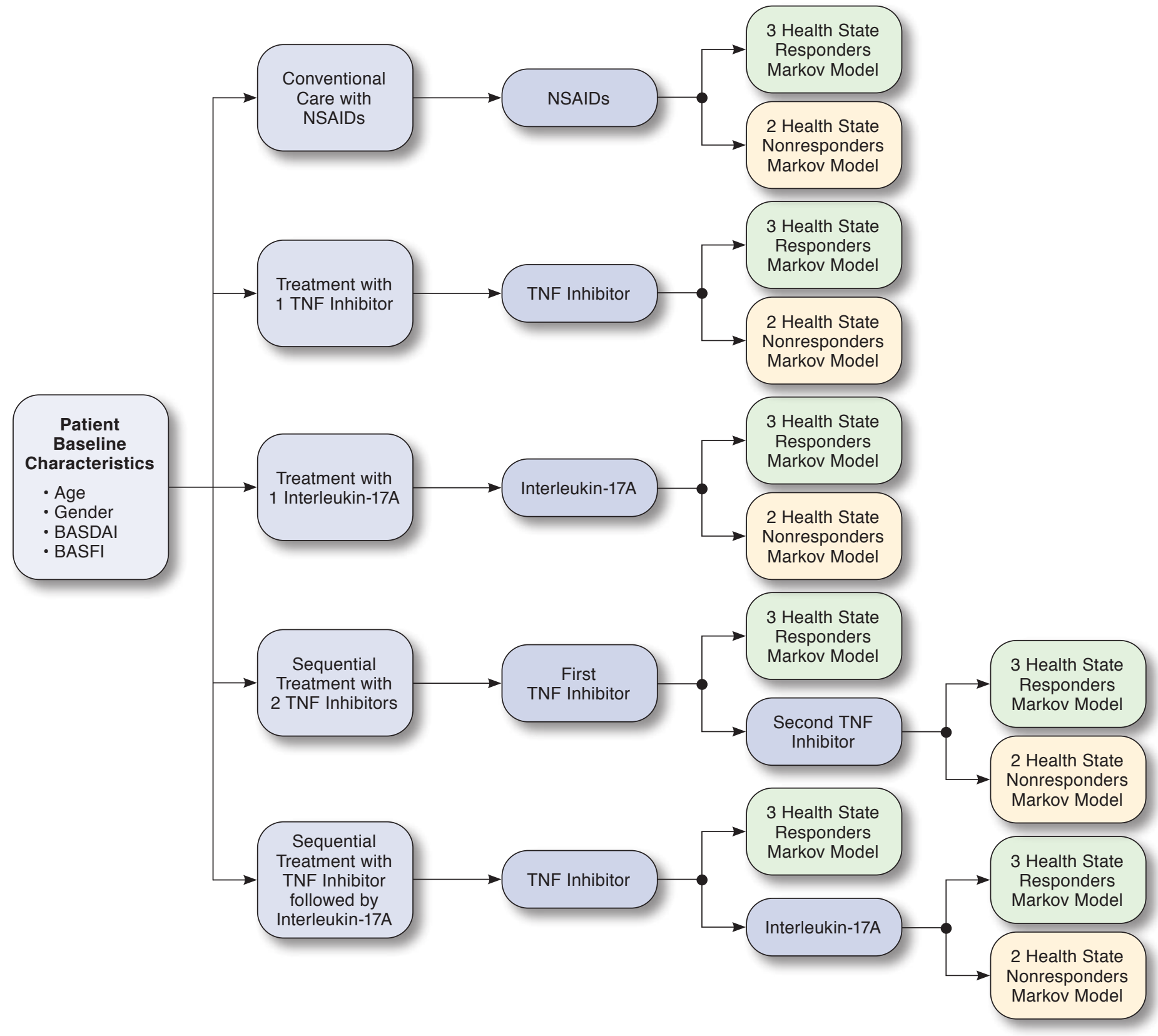

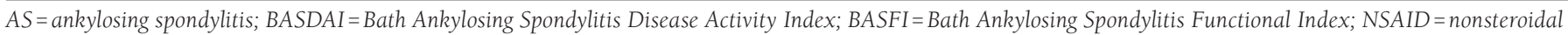
anti-inflammatory drug; TNF = tumor necrosis factor.

whether a patient would enter a responders or nonresponders Markov model. The cycle length of the Markov models was set at 1 year. The model was analyzed from a U.S. health care payer's perspective in a 10-year time horizon with a discount rate of 3\% for both costs and outcomes.
In addition, as each patient was simulated in our model, his or her demographic and clinical characteristics, treatment and overall costs, and life-years and quality-adjusted life-years (QALYs) were reported and printed out in an Excel spreadsheet for modeling verification and validation. 
Indexes for Measuring Disease Activity and Physical Functioning

Bath Ankylosing Spondylitis Disease Activity Index (BASDAI) and Bath Ankylosing Spondylitis Functional Index (BASFI) are used to measure patient-reported disease activity and physical functioning in patients with AS, respectively. ${ }^{18,19}$

BASDAI consists of 6 questions from a scale of 0 to 10, with 0 being "no problem" and 10 being "the worst problem" to assess major symptoms of AS, including fatigue, spinal pain, joint pain/swelling, areas of localized tenderness, morning stiffness duration, and morning stiffness severity. ${ }^{20-22}$ The resulting BASDAI scores range from 0 (no disease activity) to 10 (maximal disease activity), in which the cutoff score of 4 is used to define active disease. ${ }^{20-22}$

BASFI assesses a patient's physical functioning in terms of how difficult a physical task is done on a 10-point scale where 0 is "easy" and 10 is "impossible." The 10 physical tasks in BASFI include 8 items concerning the functional anatomy of a patient (bending, reaching, changing position, standing, turning, and climbing steps) and 2 items that assess a patient's ability to cope with everyday life. ${ }^{23}$ The resulting BASFI scores range from 0 (no functional impairments) to 10 (maximal impairments).

\section{Patient Population}

The population of patients with AS was based on a recent meta-analysis that included 16 randomized controlled trials for TNF inhibitors. ${ }^{13,24-39}$ Patient baseline characteristics from the clinical trials of IL-17A antibody agents were similar. Thus, we assumed that the average patient with AS in the model was a 40-year-old man (70\% male) with a weight of $73 \mathrm{~kg}$ and baseline clinical characteristics reported in Table 1. The meta-analysis reported that the adjusted baseline BASDAI and BASFI scores were different (a) between patients who received conventional care and those who received TNF inhibitors and (b) between patients who responded to treatment and those who did not respond to treatment (Table 1$){ }^{13}$

\section{Treatment Efficacy and Real-World Adherence Rate}

Treatment efficacy of biologics and conventional care in terms of overall clinical response rate was defined as 50\% improvement in BASDAI scores (BASDAI-50), as well as reduction in BASDAI and BASFI scores at 12 weeks after initial treatment (Table 1). The overall clinical response rates at 12 weeks based on evidence synthesis of the 16 clinical trials were $9.1 \%$ and $42.0 \%$ for conventional care and treatment with a TNF inhibitor, respectively. ${ }^{13}$ Similarly, the overall clinical response rates for IL-17A antibody agents were $41.5 \%$ and $19.7 \%$ for TNF inhibitor-naive patients (i.e., patients without previous treatment with a TNF inhibitor) and TNF inhibitor-experienced patients, respectively. ${ }^{15,40}$ Additionally, in sequential treatment strategies with 2 TNF inhibitors and 1 TNF inhibitor followed by an IL-17A antibody agent, the overall clinical response rates, as well as improvement in BASDAI and BASFI scores, were reduced when the second alternative TNF inhibitor or an IL-17A antibody agent was given (Table 1). ${ }^{13,15,40}$

Patients who responded to treatment would experience an initial improvement in BASDAI and BASFI scores (Table 1). Following this initial improvement, all patients would experience disease progression as a reduction in BASFI scores at an annual rate of $0.082 .{ }^{13}$ It was also assumed that patients who continue to receive a TNF inhibitor or IL-17A antibody agent would start to experience a slower disease progression rate in BASFI compared with those who receive conventional care (measured as relative risks of 0.42 and 0.153 for TNF inhibitors and IL-17A antibody agents, respectively) at 4 years and beyond after initial treatment response (i.e., time to treatment effect was assumed to be 4 years) based on the evidence synthesis (Table 1). $15,36,37,40$

Treatment withdrawal/discontinuation with biologics in AS was also common. For patients who discontinued or withdrew their treatment with a biologic, it was assumed that the BASDAI and BASFI scores would revert to baseline measures. ${ }^{13}$ Furthermore, average real-world adherence rates for TNF inhibitors, IL-17A antibody agents, and conventional care $\left(56.0 \%, 4.5 \%\right.$, and $79.5 \%$, respectively $\left.{ }^{41-43}\right)$ were incorporated in the model. Treatment costs and effectiveness were adjusted for real-world nonadherence to the treatment strategies. ${ }^{44}$

\section{Costs and Health Utilities}

The average 12-week and annual treatment costs of all TNF inhibitors (adalimumab, certolizumab pegol, etanercept, golimumab, or infliximab), 2 IL-17A antibody agents (secukinumab and ixekizumab), and conventional care with NSAIDs were estimated based on their drug costs using the 2019 wholesale acquisition costs, ${ }^{45}$ potential major treatment-related adverse events, and related drug administration and laboratory costs (Table 1). All costs were adjusted to 2019 U.S. dollars based on the medical care component of the Consumer Price Index.

\section{Health Utilities}

Health utility was estimated based on BASDAI and BASFI scores, as well as age and gender generated for each individual patient using the following equation ${ }^{13}$ :

$$
\begin{gathered}
\text { Health Utility }=0.877213-(0.032252) \times \text { BASFI Score }) \\
-(0.038409) \times(\text { BASDAI Score })-(0.027891) \times(\text { MALE })+ \\
(0.001681) \times(\text { AGE })
\end{gathered}
$$

Health utility for individual patients was updated as the disease progressed in terms of patient age and BASDAI and BASFI scores.

\section{Base-Case Analysis}

The base-case time horizon was set at 10 years and simulated 100,000 individual patients for each treatment strategy to estimate the average 10-year per-patient cost and QALYs. The 

Values and Distributions for Probabilistic Sensitivity Analysis

\begin{tabular}{|c|c|c|c|c|c|}
\hline Model Input Parameters & $\begin{array}{c}\text { Base-Case } \\
\text { Value }\end{array}$ & $\begin{array}{l}\text { Lower } \\
\text { Value }\end{array}$ & $\begin{array}{l}\text { Upper } \\
\text { Value }\end{array}$ & Distribution & References \\
\hline \multicolumn{6}{|l|}{ Model settings } \\
\hline Time horizon & 10 years & N/A & N/A & N/A & \\
\hline Discount rate for costs & $3.0 \%$ & N/A & N/A & N/A & \\
\hline Discount rate for QALYs & $3.0 \%$ & N/A & N/A & N/A & \\
\hline Markov cycle & 1.0 year & N/A & N/A & N/A & \\
\hline Time to assess treatment response & 12 weeks & N/A & N/A & N/A & 13 \\
\hline Adherence rate for TNF inhibitor class & $36.5 \%$ & $27.4 \%$ & $41.8 \%$ & Beta & 41 \\
\hline Adherence rate for IL-17A class & $64.5 \%$ & $58.3 \%$ & $70.5 \%$ & Beta & 42 \\
\hline Adherence rate for conventional care & $79.5 \%$ & $63.6 \%$ & $95.4 \%$ & Beta & 43 \\
\hline \multicolumn{6}{|l|}{ Disease progression } \\
\hline Standardized mortality rate for men with AS & 1.63 & 0.06 & 0.42 & Log-normal & 60 \\
\hline Standardized mortality rate for women with AS & 1.38 & 0.41 & 0.98 & Log-normal & 60 \\
\hline Treatment effect on BASFI progression of TNF inhibitor class (relative risk) & 0.42 & 0.25 & 0.70 & Log-normal & 13 \\
\hline Treatment effect on BASFI progression of IL-17A class (relative risk) & 0.153 & N/A & N/A & N/A & 15,40 \\
\hline Annual progression rate (BASFI) for conventional care & 0.082 & N/A & N/A & N/A & 13 \\
\hline Annual treatment withdrawal rate for biologics & $11.0 \%$ & $6.7 \%$ & $15.3 \%$ & Beta & 13 \\
\hline Time to treatment effect of biologics on disease progression (in years) & 4.00 & N/A & N/A & N/A & \\
\hline \multicolumn{6}{|l|}{ Patient baseline characteristics } \\
\hline Mean age & 40.0 years & 30.0 years & 50.0 years & Normal & 13 \\
\hline Gender (\% male) & $70.0 \%$ & N/A & N/A & N/A & 13 \\
\hline Mean weight & $85.0 \mathrm{~kg}$ & $70.0 \mathrm{~kg}$ & $100.0 \mathrm{~kg}$ & Normal & 61 \\
\hline Mean BASDAI & 6.12 & N/A & N/A & Correlated normal & 13 \\
\hline Mean BASFI & 5.28 & N/A & N/A & Correlated normal & 13 \\
\hline Mean BASDAI for responders in conventional care & 4.01 & 3.89 & 4.13 & Correlated normal & 13 \\
\hline Mean BASDAI for nonresponders in conventional care & 6.33 & 6.21 & 6.45 & Correlated normal & 13 \\
\hline Mean BASDAI for responders in TNF inhibitor class & 4.80 & 4.68 & 4.92 & Correlated normal & 13 \\
\hline Mean BASDAI for nonresponders in TNF inhibitor class & 7.08 & 6.96 & 7.20 & Correlated normal & 13 \\
\hline Mean BASDAI for responders in IL-17A class for naive TNF inhibitor & 4.80 & 4.68 & 4.92 & Correlated normal & 13 \\
\hline Mean BASDAI for nonresponders in IL-17A class for naive TNF inhibitor & 7.08 & 6.96 & 7.20 & Correlated normal & 13 \\
\hline Mean BASFI for responders in conventional care & 3.52 & 3.35 & 3.69 & Correlated normal & 13 \\
\hline Mean BASFI for nonresponders in conventional care & 5.46 & 5.29 & 5.63 & Correlated normal & 13 \\
\hline Mean BASFI for responders in TNF inhibitor class & 4.20 & 4.03 & 4.37 & Correlated normal & 13 \\
\hline Mean BASFI for nonresponders in TNF inhibitor class & 6.07 & 5.90 & 6.24 & Correlated normal & 13 \\
\hline Mean BASFI for responders in IL-17A class for naive TNF inhibitor & 4.20 & 4.03 & 4.37 & Correlated normal & 13 \\
\hline Mean BASFI for nonresponders in IL-17A class for naive TNF inhibitor & 6.07 & 5.90 & 6.24 & Correlated normal & 13 \\
\hline \multicolumn{6}{|l|}{ Treatment effects of conventional care after 12 weeks } \\
\hline Overall response rate (BASDAI-50) & $9.1 \%$ & $7.3 \%$ & $10.9 \%$ & Beta & 13 \\
\hline Mean change in BASDAI for responders & -2.89 & -2.31 & -3.47 & Correlated normal & 13 \\
\hline Mean change in BASDAI for nonresponders & -0.36 & -0.29 & -0.43 & Correlated normal & 13 \\
\hline Mean change in BASFI for responders & -1.72 & -1.38 & -2.06 & Correlated normal & 13 \\
\hline Mean change in BASFI for nonresponders & -0.04 & -0.03 & -0.05 & Correlated normal & 13 \\
\hline \multicolumn{6}{|l|}{ Treatment effects of TNF inhibitor class after 12 weeks } \\
\hline Overall response rate (BASDAI-50) & $42.0 \%$ & $33.6 \%$ & $50.4 \%$ & Beta & 13 \\
\hline Reduced factor in response rate after failing to respond to a TNF inhibitor & 0.90 & N/A & N/A & N/A & 13 \\
\hline Mean change in BASDAI for responders & -3.86 & -3.09 & -4.63 & Correlated normal & 13 \\
\hline Mean change in BASDAI for nonresponders & -1.64 & -1.31 & -1.97 & Correlated normal & 13 \\
\hline Mean change in BASFI for responders & -3.08 & -2.46 & -3.70 & Correlated normal & 13 \\
\hline Mean change in BASFI for nonresponders & -0.44 & -0.35 & -0.53 & Correlated normal & 13 \\
\hline \multicolumn{6}{|l|}{ Treatment effects of IL-17A class after 12 weeks } \\
\hline Overall response rate (BASDAI-50) in naive TNF inhibitor & $41.5 \%$ & $33.6 \%$ & $50.4 \%$ & Beta & 15,40 \\
\hline Mean change in BASDAI for responders in naive TNF inhibitor & -4.60 & -2.98 & -6.22 & Correlated normal & 15,40 \\
\hline Mean change in BASDAI for nonresponders in naive TNF inhibitor & -1.01 & -0.65 & -1.36 & Correlated normal & 15,40 \\
\hline
\end{tabular}


TABLE 1 Model Input Parameters for Natural History and Treatment Effects: Base-Case, Lower, and Upper Values and Distributions for Probabilistic Sensitivity Analysis (continued)

\begin{tabular}{|c|c|c|c|c|c|}
\hline Model Input Parameters & $\begin{array}{l}\text { Base-Case } \\
\text { Value }\end{array}$ & $\begin{array}{l}\text { Lower } \\
\text { Value }\end{array}$ & $\begin{array}{l}\text { Upper } \\
\text { Value }\end{array}$ & Distribution & References \\
\hline \multicolumn{6}{|l|}{ Treatment effects of IL-17A class after 12 weeks } \\
\hline Mean change in BASFI for responders in naive TNF inhibitor & --3.75 & -2.29 & -5.20 & Correlated normal & 15,40 \\
\hline Mean change in BASFI for nonresponders in naive TNF inhibitor & -1.17 & -0.72 & -1.63 & Correlated normal & 15,40 \\
\hline Overall response rate (BASDAI-50) in experienced TNF inhibitor & $19.7 \%$ & $11.5 \%$ & $31.5 \%$ & Beta & 15,40 \\
\hline Mean change in BASDAI for responders in experienced TNF inhibitor & -4.98 & -4.00 & -5.96 & Correlated normal & 15,40 \\
\hline Mean change in BASDAI for nonresponders in experienced TNF inhibitor & -0.94 & -0.50 & -1.39 & Correlated normal & 15,40 \\
\hline Mean change in BASFI for responders in experienced TNF inhibitor & -3.79 & -2.31 & -5.27 & Correlated normal & 15,40 \\
\hline Mean change in BASFI for nonresponders in experienced TNF inhibitor & -0.73 & -0.27 & -1.18 & Correlated normal & 15,40 \\
\hline \multicolumn{6}{|l|}{ Treatment-related health care utilization and costs } \\
\hline Percent of gastrointestinal ulcers/bleeding in conventional care with NSAIDs & $1.9 \%$ & $1.2 \%$ & $2.5 \%$ & Beta & 65 \\
\hline Percent of serious infection in TNF inhibitors & $3.5 \%$ & N/A & N/A & N/A & 13 \\
\hline Percent of tuberculosis reactivation in TNF inhibitors & $2.0 \%$ & N/A & N/A & N/A & 13 \\
\hline Percent of serious infection and tuberculosis reactivation in IL-17A & $0.8 \%$ & $0.4 \%$ & $1.2 \%$ & N/A & $13-17,40$ \\
\hline $\begin{array}{l}\text { Average cost of gastrointestinal ulcers/bleeding from conventional care with } \\
\text { NSAIDs }\end{array}$ & $\$ 5,150$ & N/A & N/A & N/A & 66 \\
\hline Average cost of serious infection from biologics & $\$ 19,072$ & N/A & N/A & N/A & 62 \\
\hline Average cost of tuberculosis treatment & $\$ 19,000$ & N/A & N/A & N/A & 63 \\
\hline Cost of tuberculosis screening & $\$ 8.25$ & N/A & N/A & N/A & 64 \\
\hline Cost of antinuclear antibodies & $\$ 86$ & N/A & N/A & N/A & 64 \\
\hline Cost of double stranded DNA & $\$ 124$ & N/A & N/A & N/A & 64 \\
\hline Cost of lab monitoring (CBC, ESR, LFT, CRP) & $\$ 187$ & N/A & N/A & N/A & 64 \\
\hline Cost of chest x-ray & $\$ 23$ & N/A & N/A & N/A & 64 \\
\hline Cost of physician office visit & $\$ 110$ & N/A & N/A & N/A & 64 \\
\hline Adalimumab (40 mg/0.8 mL × 2 prefilled syringes) & $\$ 5,174$ & N/A & N/A & N/A & 45 \\
\hline Certolizumab (200 mg/lmL) & $\$ 4,327$ & N/A & N/A & N/A & 45 \\
\hline Etanercept $(50 \mathrm{mg} / \mathrm{lmL})$ & $\$ 1,294$ & N/A & N/A & N/A & 45 \\
\hline Golimumab (50 mg/0.5mL) & $\$ 4,809$ & N/A & N/A & N/A & 45 \\
\hline Infliximab (100 mg) & $\$ 1,168$ & N/A & N/A & N/A & 45 \\
\hline Secukinumab (150 mg/lmL) & $\$ 5,541$ & N/A & N/A & N/A & 45 \\
\hline Ixekizumab (80 mg/lmL) & $\$ 5,690$ & N/A & N/A & N/A & 45 \\
\hline \multicolumn{6}{|l|}{ Overall treatment cost } \\
\hline Average TNF inhibitor (12-week cost) & $\$ 21,913$ & $\$ 17,164$ & $\$ 36,261$ & Log-normal & 45,64 \\
\hline Average IL-17A antibody (12-week cost) & $\$ 34,366$ & $\$ 27,493$ & $\$ 41,240$ & Log-normal & 45,64 \\
\hline Conventional care (12-week cost) & $\$ 743$ & $\$ 595$ & $\$ 892$ & Log-normal & 45,64 \\
\hline Average TNF inhibitor (annual cost) & $\$ 70,864$ & $\$ 56,692$ & $\$ 85,037$ & Log-normal & 45,64 \\
\hline Average IL-17A antibody (annual cost) & $\$ 73,004$ & $\$ 58,403$ & $\$ 87,605$ & Log-normal & 45,64 \\
\hline Conventional care (annual cost) & $\$ 2,130$ & $\$ 1,704$ & $\$ 2,556$ & Log-normal & 45,64 \\
\hline
\end{tabular}

Notes: All drug costs were based on 2019 wholesale acquisition cost from the online RED BOOK. ${ }^{45}$ All other costs were adjusted to 2019 U.S. dollars based on the Consumer Price Index.

AS = ankylosing spondylitis; BASDAI = Bath Ankylosing Spondylitis Disease Activity Index; BASFI=Bath Ankylosing Spondylitis Functional Index; IL-17A=interleukin-17A monoclonal antibody; N/A = not applicable; NSAID = nonsteroidal anti-inflammatory drug; QALY=quality-adjusted life-year; TNF=tumor necrosis factor.

incremental cost-effectiveness ratio (ICER) was calculated as the ratio of the incremental difference in the average perpatient costs $(\triangle \mathrm{COST})$ to the incremental QALYs $(\triangle \mathrm{QALY})$ between treatment strategies $\mathrm{A}$ and $\mathrm{B}$, defined as:

$$
I C E R=\triangle C O S T \div \triangle Q A L Y=(C O S T A-\operatorname{COSTB}) \div
$$

(QALYA-QALYB)
The resulting ICER, therefore, can be interpreted as the average cost per 1 QALY gained if using treatment strategy A instead of treatment strategy B over the 10-year time horizon. Furthermore, cost-effectiveness frontier analysis was performed to determine optimal treatment strategy at different willingness-to-pay (WTP) thresholds. 


\section{Cost-Effectiveness of Treatment Strategies with Biologics in Accordance with Treatment Guidelines for Ankylosing Spondylitis: A Patient-Level Model}

\begin{tabular}{|c|c|c|c|c|c|}
\hline Treatment Strategy & Total Cost & Incremental Cost & Total QALY & Incremental QALY & ICER \\
\hline \multicolumn{6}{|l|}{ Base case } \\
\hline Conventional care & $\$ 19,765$ & - & 4.675 & - & Reference \\
\hline 1 TNF inhibitor & $\$ 130,302$ & $\$ 110,537$ & 5.410 & 0.735 & $\$ 150,397 /$ QALY \\
\hline 1 IL-17A antibody agent & $\$ 159,934$ & $\$ 139,169$ & 5.499 & 0.825 & $\$ 168,755 /$ QALY \\
\hline TNF inhibitor followed by IL-17A & $\$ 179,118$ & $\$ 159,353$ & 5.893 & 1.352 & $\$ 130,813 /$ QALY \\
\hline 2 TNF inhibitors & $\$ 190,553$ & $\$ 170,788$ & 5.919 & 1.379 & $\$ 137,289 / \mathrm{QALY}$ \\
\hline \multicolumn{6}{|c|}{ Similar adherence rate (56\%) for TNF inhibitors and IL-17A antibody agents } \\
\hline Conventional care & $\$ 19,765$ & - & 4.675 & - & Reference \\
\hline 1 TNF inhibitor & $\$ 130,302$ & $\$ 110,537$ & 5.410 & 0.735 & $\$ 150,397 /$ QALY \\
\hline 1 IL-17A antibody agent & $\$ 145,046$ & $\$ 125,281$ & 5.473 & 0.789 & $\$ 157,035 /$ QALY \\
\hline TNF inhibitor followed by IL-17A & $\$ 175,380$ & $\$ 155,615$ & 5.885 & 1.210 & $\$ 128,601 / \mathrm{QALY}$ \\
\hline 2 TNF inhibitors & $\$ 190,553$ & $\$ 170,788$ & 5.919 & 1.244 & $\$ 137,289 /$ QALY \\
\hline \multicolumn{6}{|c|}{ High annual treatment discontinuation/withdrawal rate $(30 \%)$} \\
\hline Conventional care & $\$ 19,871$ & - & 4.646 & - & Reference \\
\hline 1 TNF inhibitor & $\$ 89,327$ & $\$ 69,617$ & 5.182 & 0.536 & $\$ 129,527 /$ QALY \\
\hline 1 IL-17A antibody agent & $\$ 110,834$ & $\$ 90,963$ & 5.228 & 0.582 & $\$ 156,311 / \mathrm{QALY}$ \\
\hline TNF inhibitor followed by IL-17A & $\$ 125,175$ & $\$ 105,304$ & 5.561 & 0.916 & $\$ 115,008 / \mathrm{QALY}$ \\
\hline 2 TNF inhibitors & $\$ 128,059$ & $\$ 108,188$ & 5.549 & 0.904 & $\$ 119,740 / \mathrm{QALY}$ \\
\hline \multicolumn{6}{|c|}{ Using baseline BASDAI and BASFI scores from clinical trials of IL-17A } \\
\hline Conventional care & $\$ 19,765$ & - & 4.136 & - & Reference \\
\hline 1 TNF inhibitor & $\$ 130,302$ & $\$ 110,537$ & 4.936 & 0.800 & $\$ 138,452 / \mathrm{QALY}$ \\
\hline 1 IL-17A antibody agent & $\$ 159,934$ & $\$ 139,169$ & 5.029 & 0.893 & $\$ 155,807 / \mathrm{QALY}$ \\
\hline TNF inhibitor followed by IL-17A & $\$ 179,118$ & $\$ 159,353$ & 5.416 & 1.280 & $\$ 124,461 /$ QALY \\
\hline 2 TNF inhibitors & $\$ 190,553$ & $\$ 170,788$ & 5.442 & 1.306 & $\$ 130,771 /$ QALY \\
\hline \multicolumn{6}{|c|}{ Immediate treatment effect on BASFI measure } \\
\hline Conventional care & $\$ 19,765$ & - & 4.675 & - & Reference \\
\hline 1 TNF inhibitor & $\$ 130,302$ & $\$ 110,537$ & 5.420 & 0.746 & $\$ 148,232 / \mathrm{QALY}$ \\
\hline 1 IL-17A antibody agent & $\$ 159,934$ & $\$ 139,169$ & 5.515 & 0.840 & $\$ 165,620 / \mathrm{QALY}$ \\
\hline TNF inhibitor followed by IL-17A & $\$ 179,118$ & $\$ 159,353$ & 5.913 & 1.238 & $\$ 128,702 / \mathrm{QALY}$ \\
\hline 2 TNF inhibitors & $\$ 190,553$ & $\$ 170,788$ & 5.935 & 1.260 & $\$ 135,495 /$ QALY \\
\hline \multicolumn{6}{|c|}{ Alternate health utility estimating equation } \\
\hline Conventional care & $\$ 19,765$ & - & 4.025 & - & Reference \\
\hline 1 TNF inhibitor & $\$ 130,302$ & $\$ 110,537$ & 4.866 & 0.841 & $\$ 131,508 /$ QALY \\
\hline 1 IL-17A antibody agent & $\$ 159,934$ & $\$ 139,169$ & 5.007 & 0.982 & $\$ 141,754 /$ QALY \\
\hline TNF inhibitor followed by IL-17A & $\$ 179,118$ & $\$ 159,353$ & 5.402 & 1.377 & $\$ 115,717 /$ QALY \\
\hline 2 TNF inhibitors & $\$ 190,553$ & $\$ 170,788$ & 5.418 & 1.393 & $\$ 122,623 / \mathrm{QALY}$ \\
\hline
\end{tabular}

\section{Sensitivity Analysis}

Probabilistic sensitivity analysis (PSA) was performed by generating 10,000 samples of model probabilistic parameters, and within each sample, 10,000 patients were simulated (i.e., the model ran 100,000,000 simulations for each treatment strategy). The probabilistic parameters were created by varying (a) the overall clinical response rates at 12-week treatment, baseline as well as mean changes in BASDAI and BASFI measures of responders and nonresponders for TNF inhibitor, IL-17A antibody agent, and conventional care with NSAIDs, treatment effect on BASFI progression of biologics, annual progression rate of conventional care on BASFI, annual withdrawal rate of biologics, real-world adherence rates, and standardized mortality rates within their 95\% confidence intervals in the assumed normal, correlated normal, log-normal, or beta distribution and (b) overall average treatment costs within $\pm 20 \%$ of their mean (base-case) values in the log-normal distribution (Table 1). 
FIGURE 2 Cost-Effectiveness Acceptability Curves for Conventional Care with NSAIDs, 1 TNF Inhibitor, an IL-17A Antibody Agent, Sequential Treatment Strategy with 2 TNF Inhibitors, and Sequential Treatment Strategy with a TNF Inhibitor Followed by an IL-17A Antibody Agent

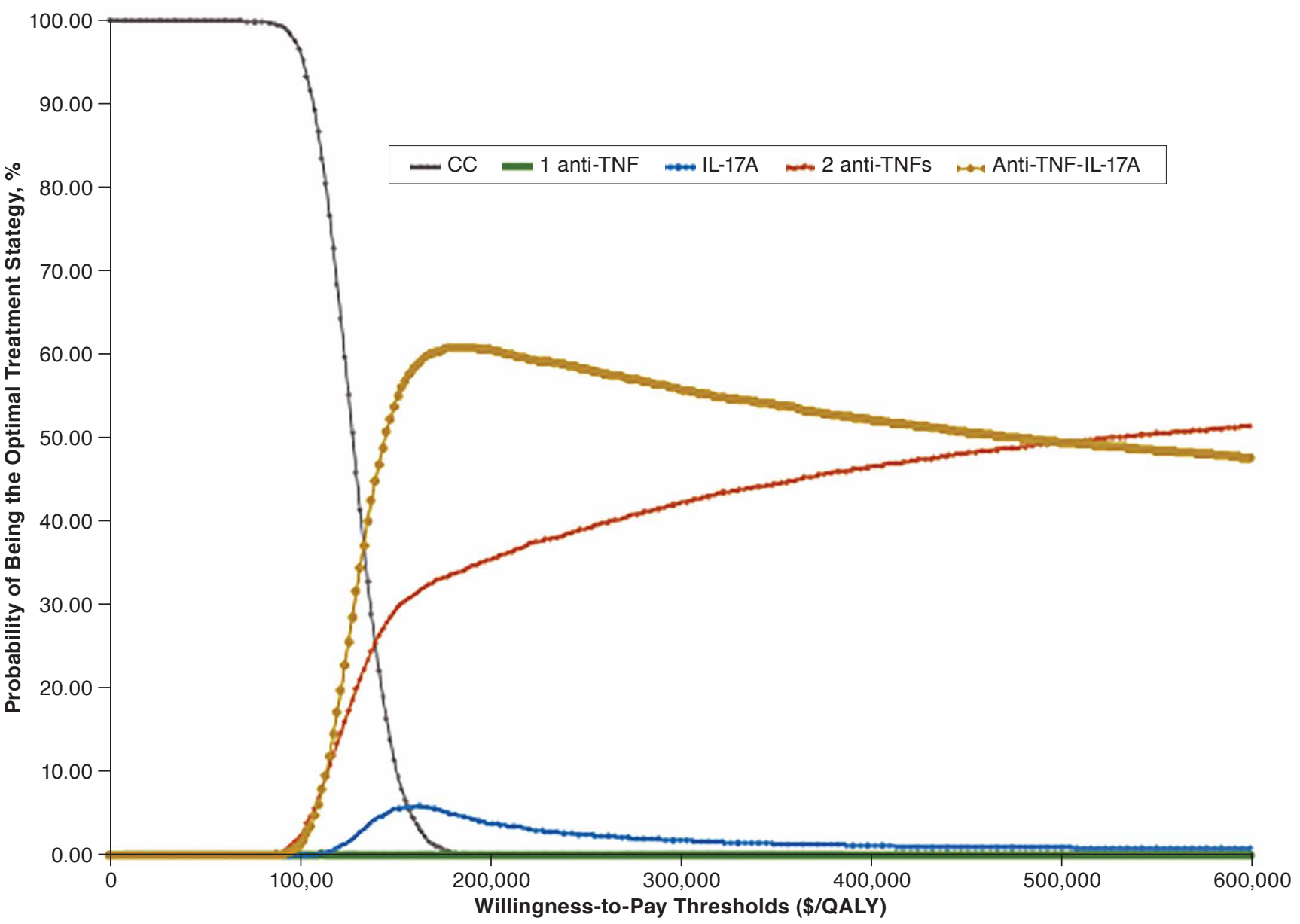

$C C=$ conventional care; IL-17A = interleukin-17a monoclonal antibody; NSAID = nonsteroidal anti-inflammatory drug; QALY=quality-adjusted life-year; TNF=tumor necrosis factor.

In addition, we explored several scenarios where time to treatment effect on BASFI scores occurs immediately after initiating treatment instead of 4 years after, similar real-world adherence rate for all TNF inhibitors and IL-17A antibody agents, baseline BASDAI and BASFI scores from clinical trials for IL-17A antibody agent (secukinumab), ${ }^{15,40}$ high percentage of treatment discontinuation/withdrawal with biologics, and an alternate health utility estimated equation ${ }^{46}$ :

$$
\begin{gathered}
\text { Health Utility }=0.923-(0.0432) \times(\text { BASFI Score }) \\
-(0.0402) \times(\text { BASDAI Score })
\end{gathered}
$$

With multiple treatment strategies, cost-effectiveness frontier analysis was performed to identify the optimal strategy at different WTP thresholds. ${ }^{47}$

\section{Results}

\section{Base-Case Cost-Effectiveness Analysis Results}

Over a 10-year time horizon and 100,000 simulated patients for each treatment strategy, base-case results produced average total discounted per-patient costs of $\$ 19,765$, $\$ 130,302$, $\$ 159,934, \$ 190,553$, and $\$ 179,118$ and QALYs per patient of $4.675,5.410,5.499,5.919$, and 5.893 for conventional care, treatment strategies with 1 TNF inhibitor, an IL-17A agent, 2 TNF inhibitors, and a TNF inhibitor followed by an IL-17A agent, respectively (Table 2). Compared with conventional care, the treatment strategies with 1 TNF inhibitor, an IL-17A agent, 2 TNF inhibitors, and a TNF inhibitor followed by an IL-17A agent yielded ICERs of $\$ 150,397, \$ 168,755, \$ 137,289$, and $\$ 130,813$ per 1 additional QALY gained, respectively. 


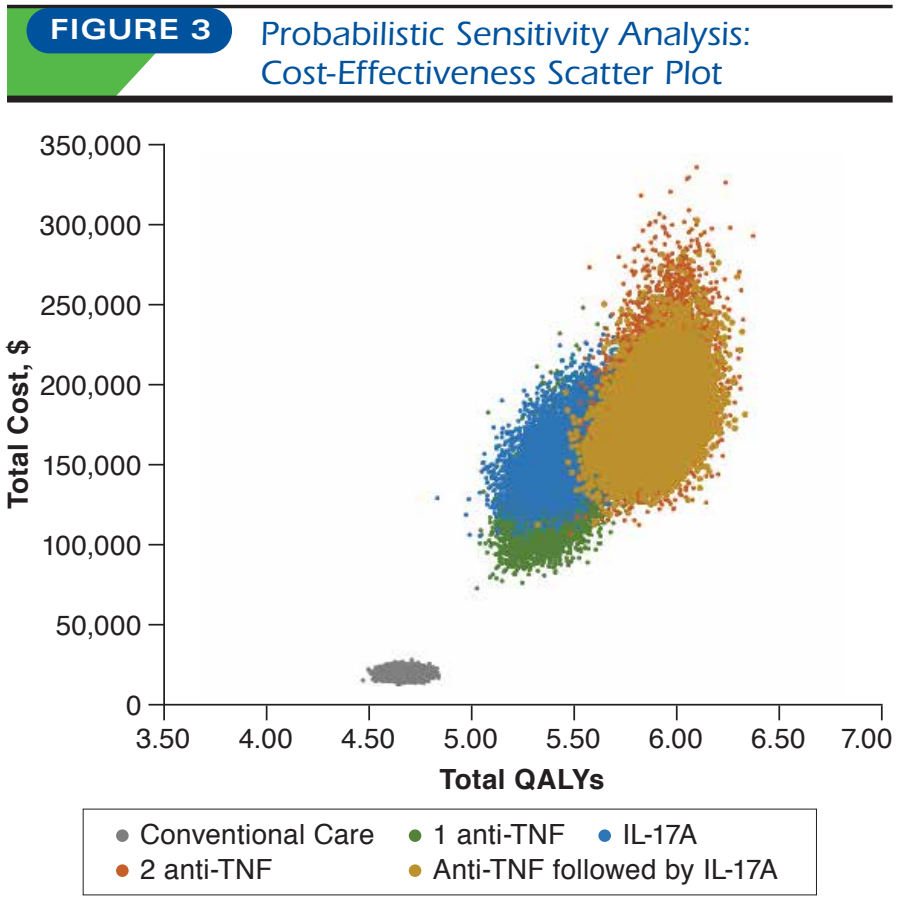

$C C=$ conventional care; IL-17A = interleukin-17a monoclonal antibody; NSAID = nonsteroidal anti-inflammatory drug; QALY= quality-adjusted life-year; TNF = tumor necrosis factor

In addition, cost-effectiveness frontier analysis showed that optimal treatments at WTP thresholds $\leq \$ 130,813$ per QALY, between $\$ 130,813$ per QALY and $\$ 442,728$ per QALY, and $>\$ 442,728$ per QALY were conventional care, sequential treatment strategies with 1 TNF inhibitor followed by an IL-17A agent, and 2 TNF inhibitors, respectively.

\section{Sensitivity Analysis Results}

Cost-effectiveness acceptability curves indicated that at the WTP threshold of $\$ 100,000$ per QALY, conventional care was the most cost-effective strategy among all treatment strategies with 95\% certainty (Figure 2). In addition, the costeffectiveness scatterplot showed that all treatment strategies with 1 TNF inhibitor, an IL-17A agent, 2 TNF inhibitors, and a TNF inhibitor followed by an IL-17A agent clearly yielded more QALYs but was more costly than conventional care (Figure 3). All 5 scenario analyses of time to treatment effect on BASFI scores occur immediately after initiating treatment instead of 4 years after, similar real-world adherence rate (56\%) for all TNF inhibitors and IL-17A antibody agents, baseline BASDAI and BASFI scores from clinical trials for IL-17A antibody agents, high percentage of treatment discontinuation/ withdrawal (30\%) with biologics, and an alternate health utility estimated equation yielded very close results, where optimal treatment strategy was the sequential treatment strategy with 1 TNF inhibitor followed by an IL-17A antibody agent at the WTP thresholds above $\$ 128,702$ per QALY (Table 2). Below these WTP thresholds, conventional care therapy was the optimal treatment strategy.

\section{Discussion}

Previous cost-effectiveness studies in AS have typically been comparisons among TNF inhibitors, ${ }^{13,48,49}$ individual TNF inhibitors compared with conventional care with NSAIDs, $, 13,46,48-54$ or more recently with IL-17A antibody agents. ${ }^{40,55,56}$ This economic analysis was the first study to investigate the costeffectiveness of treatment strategies in accordance with the current treatment guidelines for AS, specifically the sequential use of 2 TNF inhibitors and a TNF inhibitor followed by an IL-17A antibody agent. Our analysis showed that all treatment strategies with biologics, monotherapy or sequential therapy, would unlikely be cost-effective compared with conventional care at the common WTP of $\$ 100,000$ per QALY. However, at a higher WTP threshold of $\$ 150,000$ per QALY, the sequential treatment strategies with 2 TNF inhibitors and 1 TNF inhibitor followed by an IL-17A antibody agent appeared to be costeffective compared with conventional care. Our analysis results of treatment strategy with 1 biologic, a TNF inhibitor, or IL-17A antibody agent, relative to conventional care, was different from previous non-U.S. cost-effectiveness studies, ${ }^{13,46,50-52,54}$ where the treatment was likely cost-effective under acceptable WTP thresholds because acquisition costs of biologics in other countries were much lower than they are in the United States.

A recent systematic review of cost-effectiveness studies in treatment of AS (2012) evaluated the quality of the studies and provided a critical review of the studies in 6 important areas ${ }^{57}$ : (1) the role of indirect costs, (2) quality of input description in the study models, (3) alternative treatment comparators, (4) assumptions for long-term modeling, (5) effects of upfront costs in treatment with TNF inhibitors, and (6) adequacy of BASDAI/BASFI scales for effectiveness. In the current study, we modeled our analysis following critical evaluations of the important issues, except for the indirect costs, based on this systematic review..$^{57}$ The quality of our model input parameters was based mainly on the comprehensive meta-analysis from all clinical trials of the TNF inhibitors for AS disease. ${ }^{13}$ The treatment alternative comparators in our analysis were not among the 5 equally effective TNF inhibitors or between the equally recommended 2 IL-17A antibody agents, but rather the treatment strategies with 1 TNF inhibitor, an IL-17A agent, 2 TNF inhibitors, a TNF inhibitor followed by an IL-17A agent, and conventional care with NSAIDs.

Our analysis was modeled based on a 10-year time horizon, which is long enough to model progression of disease but not too long, since treatment in AS disease is changing rapidly with time. As recommended, an initial treatment period of 12 weeks 
was modeled in our study to determine clinical response, thus, the effects of upfront costs in treatment with TNF inhibitors and IL-17A agents were significantly reduced. Finally, for QALY outcomes, our model applied a health utility equation based on the BASDAI and BASFI scores (reflecting disease activity and functional impairment, respectively), as well as patient age and gender in the base case. ${ }^{13}$ In addition, a different health utility equation involving only the BASDAI and BASFI scores was used for our sensitivity analysis. ${ }^{46}$ The overall cost-effectiveness results were slightly changed, specifically with the ICER of the sequential treatment strategy, with 1 TNF inhibitor followed by an IL-17A antibody agent compared with conventional care lowered to $\$ 115,717$ per QALY from the baseline of $\$ 130,813$ per QALY.

The current analysis was modeled at an individual level that addressed the "memoryless" limitation of cohort Markov models, which do not account for the effect of individual patient history on future events or on clinical outcomes whose rates depend on time of occurrence. ${ }^{58}$ As a result, the individuallevel approach has certain advantages in modeling patient heterogeneity and is especially appropriate in comparative effectiveness studies.

Our analysis has several advantages, including modeling at an individual level where the stochastic relationships among patient characteristics (age, gender, BASDAI, and BASFI), health care costs, and health utility were simulated, reflecting their nonlinear relationships to better estimate the overall per-patient cost and QALYs. The main clinical data used in our simulated model came from a comprehensive meta-analysis of all clinical trials using TNF inhibitors for AS disease, which provided the highest evidence-based results compared with individual clinical trials for each TNF inhibitor. In addition, our analysis addressed the real-world question of whether further treatment with a second alternative TNF inhibitor or an IL-17A antibody agent in patients who did not respond with the initial TNF inhibitor would be cost-effective at the common WTP range between $\$ 100,000$ per QALY and \$150,000 per QALY.

\section{Limitations}

As with all economic modeling studies, our economic analysis of treatment strategies in accordance with treatment guidelines for patients with AS should be seen in the light of methodological limitations and unavoidable assumptions. First, most of our model inputs for clinical outcomes were based on a recent meta-analysis of all TNF inhibitors approved to treat patients with ankylosing spondylitis. ${ }^{13}$ The aggregate data of all TNF inhibitors were used instead of individual information from each TNF inhibitor. As such, we did not distinguish individual
TNF inhibitors but used the average overall cost of all TNF inhibitors in our analysis. The analysis was, however, aligned with treatment guidelines for AS disease where no specific TNF inhibitors were recommended over the others. In accounting for difference in costs of TNF inhibitors, we performed a PSA with $\pm 20 \%$ the average overall cost of TNF inhibitors in the model. Moreover, no meta-analysis has been done on the IL-17A antibody agents, so our analysis on IL-17A antibody agents was mainly based on secukinumab instead of the class aggregate data.

Second, our analysis encompassed long-term estimation beyond the time frame of clinical trials, thus, assumptions regarding the progression of functional limitations and treatment discontinuation rates were necessary. In the model, the progression of functional loss from the disease was captured by an annual increase in the BASFI score of $0.082 .{ }^{13}$ For patients who responded to TNF inhibitor or IL-17A antibody treatment, it was assumed that the annual BASFI progression would be reduced by a factor (relative risk) of 0.42 or 0.153 , respectively, at 4 years and thereafter. ${ }^{13,15,40}$ To account for treatment discontinuation, an annual withdrawal rate of $11 \%$ (95\% $\mathrm{CI}=6.7 \%-15.3 \%)$ for treatment with a biologic was assumed in the model. ${ }^{13}$ In our sensitivity analysis, immediate treatment effect of treatment with TNF inhibitors on BASFI scores or a high annual discontinuation rate of $30 \%$ only yielded minimal changes in overall cost-effectiveness results.

Finally, income loss and indirect cost implications from impairment of productivity might be important in AS disease but was not included in our analysis. Recently, a non-U.S. study reported an increase in work productivity with biologic therapy by patients with $\mathrm{AS}^{59}$; thus, cost-effectiveness results for biologic therapy might be improved from a societal perspective. However, estimating indirect costs or productivity loss has not been sufficient and standardized in the United States. As a result, our analysis focused only on the U.S. health care payer's perspective. Further research quantifying the cost from productivity loss in patients with AS would improve understanding from the patient and societal perspectives.

\section{Conclusions}

The current study suggested that all treatment strategies with biologics, TNF inhibitors or IL-17A agents, in the treatment guidelines for AS were not cost-effective at the common WTP of $\$ 100,000$ per QALY from the U.S. health care payer's perspective. Nevertheless, the sequential treatment with 1 TNF inhibitor followed by an IL-17A agent was considered costeffective at a higher WTP of $\$ 150,000$ per QALY. 


\section{Authors}

QUANG A. LE, PharmD, PhD; JENNY H. KANG, PharmD; and DIMITTRI DELEVRY, PharmD, Department of Pharmacy Practice and Administration, College of Pharmacy, Western University of Health Sciences, Pomona, California. SUN LEE, PharmD, Department of Clinical Sciences, Fred Wilson School of Pharmacy, High Point University, High Point, North Carolina.

AUTHOR CORRESPONDENCE: Quang A. Le, PharmD, PhD, Associate Professor, Department of Pharmacy Practice and Administration, College of Pharmacy, Western University of Health Sciences, 309 E. Second St., Pomona, CA 91766-1854.

Tel.: 909.706.3821; Email: qle@westernu.edu.

\section{DISCLOSURES}

No outside funding supported this study. The authors have nothing to disclose.

Primary findings of this study were presented in part at the International Society for Pharmacoeconomics and Outcomes Research (ISPOR) in Baltimore, MD, May 2018

\section{REFERENCES}

1. Sieper J, Braun J, Rudwaleit M, Boonen A, Zink A. Ankylosing spondylitis: an overview. Ann Rheum Dis. 2002;61(Suppl 3):iii8-18.

2. Walsh J, Hunter T, Schroeder K, Bolce R. Trends in diagnostic prevalence and treatment patterns of male and female ankylosing spondylitis patients in the United States, 2006-2016. BMC Rheumatol. 2019;3:39.

3. Kotsis K, Voulgari PV, Drosos AA, Carvalho AF, Hyphantis T. Health-related quality of life in patients with ankylosing spondylitis: a comprehensive review. Expert Rev Pharmacoecon Outcomes Res. 2014;14(6):857-72

4. Franke LC, Ament AJ, van de Laar MA, Boonen A, Severens JL. Costof-illness of rheumatoid arthritis and ankylosing spondylitis. Clin Exp Rheumatol. 2009;27(4 Suppl 55):S118-23.

5. Kobelt G, Andlin-Sobocki P, Brophy S, Jonsson L, Calin A, Braun J. The burden of ankylosing spondylitis and the cost-effectiveness of treatment with infliximab (Remicade). Rheumatology. 2004;43:1158-66.

6. Greenberg JD, Palmer JB, Li Y, Herrera V, Tsang Y, Liao M. Healthcare resource use and direct costs in patients with ankylosing spondylitis and psoriatic arthritis in a large U.S. cohort. J Rheumatol. 2016;43(1):88-96.

7. Boonen A, de Vet H, van der Heijde D, van der Linden S. Work status and its determinants among patients with ankylosing spondylitis. A systematic literature review. J Rheumatol. 2001;28(5):1056-62.

8. Ward MM, Deodhar A, Gensler LS, et al. 2019 update of the American College of Rheumatology/Spondylitis Association of America/ Spondyloarthritis Research and Treatment Network Recommendations for the Treatment of Ankylosing Spondylitis and Nonradiographic Axial Spondyloarthritis. Arthritis Rheumatol. 2019;71(10):1599-613.

9. Callhoff J, Sieper J, Weib A, Zink A, Listing J. Efficacy of TNFa blockers in patients with ankylosing spondylitis and non-radiographic axial spondyloarthritis: a meta-analysis. Ann Rheum Dis. 2015;74(6):1241.

10. Machado MA, Barbosa MM, Almeida AM, et al. Treatment of ankylosing spondylitis with TNF blockers: a meta-analysis. Rheumatol Int. 2013;33(9):2199-213
11. Schabert VF, Watson C, Joseph GJ, et al. Cost of tumor necrosis factor blockers per treated patients using real-world drug data in a managed care population. J Manag Care Pharm. 2013;19(8):621-30. Available at: https:// www.jmcp.org/doi/10.18553/jmcp.2013.19.8.621.

12. Maxwell LJ, Zochling J, Boonen A, et al. TNF-alpha inhibitors for ankylosing spondylitis. Cochrane Database Syst Rev. 2015;(4):CD005468

13. Corbett M, Soares M, Jhuti G, et al. Tumour necrosis factor- $\alpha$ inhibitors for ankylosing spondylitis and non-radiographic axial spondyloarthritis: a systematic review and economic evaluation. Health Technol Assess. 2016;20(9):1-334.

14. Baeten D, Sieper J, Braun J, et al. Secukinumab, an interleukin-17A inhibitor, in ankylosing spondylitis. N Engl J Med. 2015;373(26):2534-48,

15. National Institute for Health and Care Excellence. Secukinumab for active ankylosing spondylitis after treatment with nonsteroidal antiinflammatory drugs or TNF-alpha inhibitors (TA407). Technology appraisal guidance. September 28, 2016. Available at: https://www.nice.org.uk/ guidance/ta407/resources/secukinumab-for-active-ankylosing-spondylitisafter-treatment-with-nonsteroidal-antiinflammatory-drugs-or-tnfalphainhibitors-pdf-82604547798469. Accessed September 4, 2020.

16. Van der Heijde D, Wei JC, Dougados M, et al. Ixekizumab, an interleukin-17A antagonist in the treatment of ankylosing spondylitis or radiographic axial spondyloarthritis in patients previously untreated with biological disease modifying anti-rheumatic drugs (COAST-V): 16 week results of a phase 3 randomised, double-blind, active-controlled and placebocontrolled trial. Lancet. 2018;392(10163):2441-51.

17. Deodhar A, Poddubnyy D, Pacheco-Tena C, et al. Efficacy and safety of ixekizumab in the treatment of radiographic axial spondyloarthritis: sixteen-week results from a phase III randomized, double-blind, placebocontrolled trial in patients with prior inadequate response to or intolerance of tumor necrosis factor inhibitors. Arthritis Rheumatol. 2019;71(4):599-611

18. Garrett S, Jenkinson T, Kennedy LG, Whitelock H, Gaisford P, Calin A A new approach to defining disease status in ankylosing spondylitis: the Bath Ankylosing Spondylitis Disease Activity Index. J Rheumatol. 1994;21(12):2286-91

19. Calin A, Garrett S, Whitelock H, et al. A new approach to defining functional ability in ankylosing spondylitis: the development of the Bath Ankylosing Spondylitis Functional Index. J Rheumatol. 1994;21(12):2281-85.

20. Braun J, Pham T, Sieper J, et al. International ASAS consensus statement for the use of anti-tumour necrosis factor agents in patients with ankylosing spondylitis. Ann Rheum Dis. 2003;62(9):817-24.

21. Van der Heijde D, Sieper J, Maksymowych WP, et al. 2010 Update of the international ASAS recommendations for the use of anti-TNF agents in patients with axial spondyloarthritis. Ann Rheum Dis. 2011;70(6):905-08.

22. Cohen JD, Cunin P, Farrenq V, et al. Estimation of the Bath Ankylosing Spondylitis Disease Activity Index cutoff for perceived symptom relief in patients with spondyloarthropathies. J Rheumatol. 2006;33(1):79-81.

23. Taylor AL, Balakrishnan C, Calin A. Reference centile charts for measures of disease activity, functional impairment, and metrology in ankylosing spondylitis. Arthritis Rheum. 1998;41(6):1119-25.

24. Hu Z, Xu M, Li Q, et al. Adalimumab significantly reduces inflammation and serum DKK-1 level but increases fatty deposition in lumbar spine in active ankylosing spondylitis. Int J Rheum Dis. 2012;15(4):358-65.

25. Huang F, Gu J, Zhu P, et al. Efficacy and safety of adalimumab in Chinese adults with active ankylosing spondylitis: results of a randomised, controlled trial. Ann Rheum Dis. 2014;73(3):587-94

26. Lambert RG, Salonen D, Rahman P, et al. Adalimumab significantly reduces both spinal and sacroiliac joint inflammation in patients with ankylosing spondylitis: a multicenter, randomized, double-blind, placebocontrolled study. Arthritis Rheum. 2007;56(12):4005-14 
27. van der Heijde D, Kivitz A, Schiff MH, et al. Efficacy and safety of adalimumab in patients with ankylosing spondylitis: results of a multicenter, randomized, double-blind, placebo-controlled trial. Arthritis Rheum. 2006;54(7):2136-46.

28. Landewe R, Braun J, Deodhar A, et al. Efficacy of certolizumab pegol on signs and symptoms of axial spondyloarthritis including ankylosing spondylitis: 24-week results of a double-blind randomised placebocontrolled phase 3 study. Ann Rheum Dis. 2014;73(1):39-47.

29. Barkham N, Coates LC, Keen H, et al. Double-blind placebo-controlled trial of etanercept in the prevention of work disability in ankylosing spondylitis. Ann Rheum Dis. 2010;69(11):1926-28.

30. Davis JC Jr, Van der Heijde D, Braun J, et al. Recombinant human tumor necrosis factor receptor (etanercept) for treating ankylosing spondylitis: a randomized, controlled trial. Arthritis Rheum. 2003;48(11):3230-36.

31. Dougados M, Braun J, Szanto S, et al. Efficacy of etanercept on rheumatic signs and pulmonary function tests in advanced ankylosing spondylitis: results of a randomised double-blind placebo-controlled study (SPINE). Ann Rheum Dis. 2011;70(5):799-804.

32. Gorman JD, Sack KE, Davis JC Jr. Treatment of ankylosing spondylitis by inhibition of tumor necrosis factor alpha. N Engl J Med. 2002;346(18):1349-56

33. Calin A, Dijkmans BA, Emery P, et al. Outcomes of a multicentre randomised clinical trial of etanercept to treat ankylosing spondylitis. Ann Rheum Dis. 2004;63(12):1594-600.

34. van der Heijde D, Da Silva JC, Dougados M, et al. Etanercept $50 \mathrm{mg}$ once weekly is as effective as $25 \mathrm{mg}$ twice weekly in patients with ankylosing spondylitis. Ann Rheum Dis. 2006;65(12):1572-77.

35. Inman RD, Davis JC Jr, van der Heijde D, et al. Efficacy and safety of golimumab in patients with ankylosing spondylitis: results of a randomized, double-blind, placebo-controlled, phase III trial. Arthritis Rheum. 2008;58(11):3402-12.

36. Bao C, Huang F, Khan MA, Fei K, Wu Z, Hsia EC. Golimumab administered subcutaneously every 4 weeks in Chinese patients with active ankylosing spondylitis: week 24 safety and efficacy results from a randomized, placebo-controlled study. Arthritis Rheum. 2012;64:S589.

37. Braun J, Brandt J, Listing J, et al. Treatment of active ankylosing spondylitis with infliximab: a randomised controlled multicentre trial. Lancet. 2002;359(9313):1187-93

38. Marzo-Ortega H, McGonagle D, Jarrett S, et al. Infliximab in combination with methotrexate in active ankylosing spondylitis: a clinical and imaging study. Ann Rheum Dis. 2005;64(11):1568-75.

39. Van den Bosch F, Kruithof E, Baeten D, et al. Randomized double-blind comparison of chimeric monoclonal antibody to tumor necrosis factor alpha (infliximab) versus placebo in active spondylarthropathy. Arthritis Rheum. 2002;46(3):755-65

40. Emery P, Van Keep M, Beard S, et al. Cost Effectiveness of secukinumab for the treatment of active ankylosing spondylitis in the UK. Pharmacoeconomics. 2018;36(8):1015-27.

41. Walsh JA, Adejoro O, Chastek B, Park Y. Treatment patterns of biologics in US patients with ankylosing spondylitis: descriptive analyses from a claims database. J Comp Eff Res. 2018;7(4):369-80.

42. Kiltz U, Peterlik D, Winkelmann V, et al. AB0705 AQUILA Study in Germany - real world adherence and persistence of secukinumab treatment in ankylosing spondylitis and psoriatic arthritis patients - an interim analysis. Ann Rheum Dis. 2019;78:1814-15. Available at: https://ard.bmj.com/ content/78/Suppl_2/1814.2. Accessed September 4, 2020.

43. de Klerk E, van der Linden SJ. Compliance monitoring of NSAID drug therapy in ankylosing spondylitis, experiences with an electronic monitoring device. Br J Rheumatol. 1996;35(1):60-65.
44. Le QA, Hay JW, Becker R, Wang Y. Cost-effectiveness analysis of sequential treatment of abaloparatide followed by alendronate versus teriparatide followed by alendronate in postmenopausal women with osteoporosis in the United States. Ann Pharmacother. 2019;53(2):134-43.

45. IBM Watson Health. IBM Micromedex RED BOOK. December 16, 2019. Available at: https://www.ibm.com/us-en/marketplace/micromedex-red-book. Accessed September 11, 2020.

46. Ara RM, Reynolds AV, Conway P. The cost-effectiveness of etanercept in patients with severe ankylosing spondylitis in the UK. Rheumatology. 2007;46(8):1338-44.

47. Barton GR, Briggs AH, Fenwick EA. Optimal cost-effectiveness decisions: the role of the cost-effectiveness acceptability curve (CEAC), the cost-effectiveness acceptability frontier (CEAF), and the expected value of perfection information (EVPI). Value Health. 2008;11(5):886-97.

48. Boonen A, van der Heijde D, Severens JL, et al. Markov model into the cost-utility over five years of etanercept and infliximab compared with usual care in patients with active ankylosing spondylitis. Ann Rheum Dis. 2006;65(2):201-08

49. McLeod C, Bagust A, Boland A, et al. Adalimumab, etanercept and infliximab for the treatment of ankylosing spondylitis: a systematic review and economic evaluation. Health Technol Assess. 2007;11(28):1-158.

50. Kobelt G, Andlin-Sobocki P, Maksymowych WP. The cost-effectiveness of infliximab (Remicade) in the treatment of ankylosing spondylitis in Canada. J Rheumatol. 2006;33(4):732-40.

51. Kobelt G, Sobocki P, Sieper J, Braun J. Comparison of the costeffectiveness of infliximab in the treatment of ankylosing spondylitis in the United Kingdom based on two different clinical trials. Int J Technol Assess Health Care. 2007;23(3):368-75.

52. Kobelt G, Sobocki P, Mulero J, Gratacos J, Collantes-Estevez E, Braun J. The cost-effectiveness of infliximab in the treatment of ankylosing spondylitis in Spain. Comparison of clinical trial and clinical practice data. Scand J Rheumatol. 2008:37(1):62-71

53. Neilson AR, Sieper J, Deeg M. Cost-effectiveness of etanercept in patients with severe ankylosing spondylitis in Germany. Rheumatology. 2010;49(11):2122-34.

54. Botteman MF, Hay JW, Luo MP, Curry AS, Wong RL, van Hout BA. Cost-effectiveness of adalimumab for the treatment of ankylosing spondylitis in the United Kingdom. Rheumatology. 2007;46(8):1320-28.

55. Goeree R, Chiva-Razavi S, Gunda P, Jain M, Jugl SM. Cost-effectiveness analysis of secukinumab in ankylosing spondylitis from the Canadian perspective. J Med Econ. 2019;22(1):45-52.

56. Purmonen T, Puolakka K, Mishra D, Gunda P, Martikainen J. Costeffectiveness of secukinumab compared to other biologics in the treatment of ankylosing spondylitis in Finland. Clinicoecon Outcomes Res. 2019;11:159-68.

57. Kirchhoff TD, Mittendorf T, Schmidt RE, Jablonka A, Merkesdal S. Cost-effectiveness of TNF- $\alpha$ inhibition in active ankylosing spondylitis: a systematic appraisal of the literature. Expert Rev Pharmacoecon Outcomes Res. 2012;12(3):307-17.

58. Le QA. Patient-level modeling approach using discrete-event simulation: a cost-effectiveness study of current treatment guidelines for women with postmenopausal osteoporosis. J Manag Care Spec Pharm. 2019;25(10):108995. Available at: https://www.jmcp.org/doi/10.18553/jmcp.2019.25.10.1089.

59. Claudepierre P, Van den Bosch F, Sarzi-Puttini P, Vastesaeger N, Govoni M, Kachroo S. Treatment with golimumab or infliximab reduces health resource utilization and increases work productivity in patients with ankylosing spondylitis in the QUO-VADIS study, a large, prospective reallife cohort. Int J Rheum Dis. 2019;22(6):995-1001.

60. Bakland G, Gran JT, Nossent JC. Increased mortality in ankylosing spondylitis is related to disease activity. Ann Rheum Dis. 2011;70(11):1921-25. 
61. National Center for Health Statistics. FastStats. Body measurements. June 16, 2019. Available at: https://www.cdc.gov/nchs/fastats/bodymeasurements.htm. Accessed September 4, 2020.

62. Johnston S, Kelly S, Nadkarni A, Wilson K, Limone B, Hochberg M. Poster presented at: Healthcare costs associated with serious infections among biologic-naïve rheumatoid arthritis patients initiating first-line biologic treatment. American College of Rheumatology Annual Meeting; November 14-19, 2014; Boston, MA. Available at: https://acrabstracts.org/ abstract/healthcare-costs-associated-with-serious-infections-among-biologicnaive-rheumatoid-arthritis-patients-initiating-first-line-biologic-treatment. Accessed September 4, 2020.
63. Oh P, Pascopella L, Barry PM, Flood JM. A systematic synthesis of direct costs to treat and manage tuberculosis disease applied to California, 2015. BMC Res Notes. 30;10(1):434.

64. Centers for Medicare \& Medicaid Services. Physician fee schedule. Available at: https://www.cms.gov/Medicare/Medicare-Fee-for-ServicePayment/PhysicianFeeSched. Accessed September 4, 2020.

65. Ramey DR, Watson DJ, Yu C, Bolognese JA, Curtis SP, Reicin AS. The incidence of upper gastrointestinal adverse events in clinical trials of etoricoxib vs. non-selective NSAIDs: an updated combined analysis. Curr Med Res Opin. 2005;21(5):715-22.

66. Fine M. Quantifying the impact of NSAID-associated adverse events. Am J Manag Care. 2013;19(14 Suppl):S267-S272. 


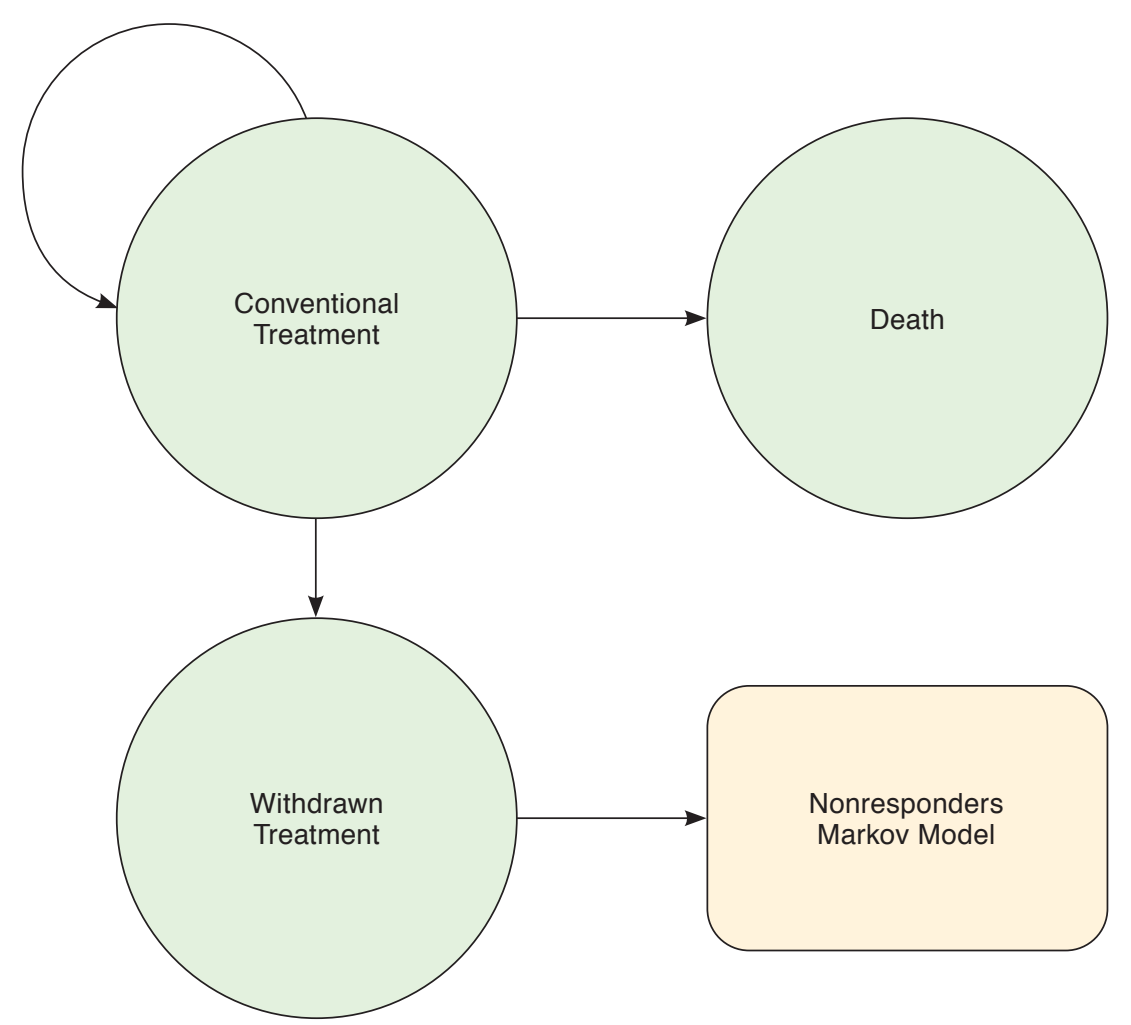




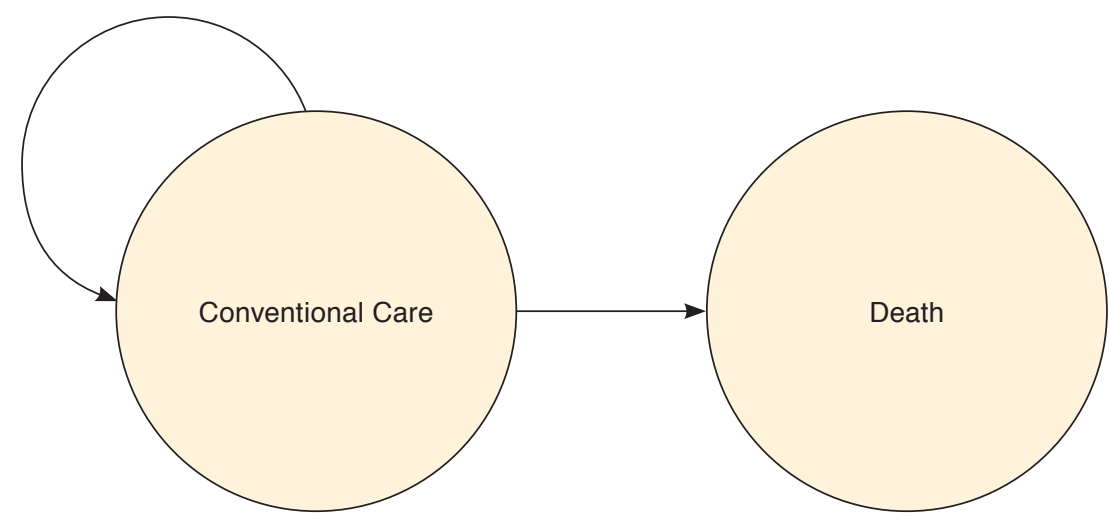

